\title{
Public perception, practices, and readiness for post Covid-19 lifestyle in Ikolaba Community, Ibadan
}

Andrew A. Olayemi

Doctoral student, Department of Arts and Social Sciences Education, University of Ibadan bimbo_andrew@yahoo.com

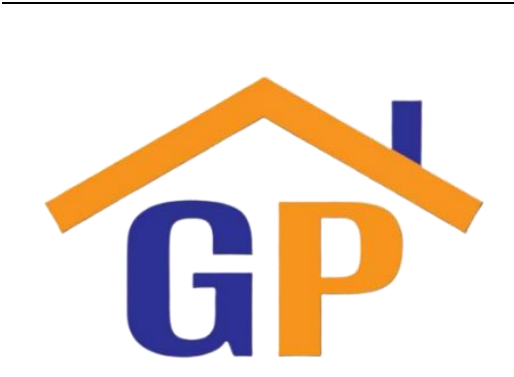

\begin{abstract}
Purpose: Besides medical researches that are focused on getting a vaccine, research on the social, economic and cultural implications of the Covid-19 virus are being done. No research has been done to assess the knowledge and practices of the people within a community of a known case of coronavirus in Ibadan metropolis, Nigeria. Therefore, this study assesses the public perception, practices of Covid-19 protocols and readiness for post lockdown.
\end{abstract}

Research methodology: Research design was survey and the method used was interview. 22 respondents participated in the study.

Article History

Received on 9 June 2020

$1^{\text {st }}$ Revision on 21 June 2020

$2^{\text {nd }}$ Revision on 26 June 2020

$3^{\text {rd }}$ Revision on 4 July 2020

$4^{\text {th }}$ Revision on 2 August 2020

$5^{\text {th }}$ Revision on 17 August 2020

Accepted on 18 August 2020
Results: The findings indicated that the public perceived the disease as a contagion and a killer. In addition, some did not observe the preventive measures while majority seem cautious. It is recommended that awareness and enlightenment should be intensified especially within the local communities by mobilizing heads of community to commence town halls campaigns.

Limitation: Finance was a major limitation because residents wanted to be compensated before participation.

Contribution: The implication of this study is that government efforts are impacting the public but more work is needed in the area of educating the public.

Keywords: Attitude, Coronavirus, Obstacles, Perception, Readiness

How to cite: Olayemi, A. A. (2020). Public perception, practices, and readiness for post Covid-19 lifestyle in Ikolaba Community, Ibadan. Journal of Social, Humanity, and Education, 1(1), 1-12.

\section{Introduction}

Historical evidence has shown that coronaviruses are a large group of viruses that are commonly transmitted through birds and mammals, with human beings particularly vulnerable to infection and transmission of the virus (Schoeman \& Fielding, 2019). According to the World Health Organization (WHO), the past outbreaks of coronaviruses such as Severe Acute Respiratory Syndrome Coronavirus (SARS-CoV) and Middle East Respiratory Syndrome- Coronavirus (MERS-CoV) in 2003 and 2015 respectively show similarities to the novel coronavirus. The novel coronavirus disease 2019 (Covid-19) was first discovered in the city of Wuhan, Hubei Province, China in December 2019. This virus is currently ravaging almost every country of the world and nearly all countries in Africa have reported a case. Besides, it is projected that Africa will have its fair share of the worst effects of this disease by the end of the pandemic (The Economists, 2020). This projection is not far-fetched bearing in mind Africa's fragile health, economic and financial systems which may not be able to withstand the pressures of a pandemic of the nature of Covid-19. In Nigeria, the index case was reported in Lagos on February 27, 2020 with an Italian man and today over 10, 000 Nigerians have contracted the virus in 34 States with the Federal Capital Territory out of the 36 States that make up the Federal Republic of Nigeria. Ibadan, the capital city of Oyo State in Nigeria, recorded its first case on March 17, 2020 with a United Kingdom returnee. Consequent upon this, Oyo State government 
imposed a partial lock down in the State with dusk to dawn curfew, closure of all educational, religious and public service institutions, ban on public gatherings of all kinds exceeding twenty persons, ban on inter-state travels, among other measures to forestall community spread of the novel Coronavirus in the State. At the moment Oyo State has recorded over 500 cases.

The Nigeria Centre for Disease Control (NCDC) in collaboration with the State Ministry of Health swung into action to trace, test and treat persons who had come in contact with a known case and advice appropriately. According to Sauer (2020), Covid-19 is a contagious respiratory related illness that is often transmitted through the eyes, nose and mouth via droplets from coughs and sneezes, close contact with infected persons and touching of contaminated surfaces. It takes between 1 to 14 days for the virus to manifest in anyone who will show symptoms and the symptoms include cough, fever, and shortness of breath. It is pertinent to note that a new symptom is being reported by health experts in addition to the highlighted ones which is loss of smell. Pandemics are not new to the world, in fact over 10 pandemics have been declared between the last half of the 20th century till date, that is, 1950 - 2020. In each of these cases, no serious alteration to humans living habits between pre and post pandemic periods. However, the case of Covid-19 also known as coronavirus is likely to be different from other pandemics that had infested human beings in the past. Coronavirus is not completely strange but this strand of the virus is novel and as a result scientists are studying it with a view to developing a vaccine. While these efforts are on-going, there is the need for a change in human behaviour and lifestyle pattern in order for the spread of the virus to be contained. Based on the conjectures from the science community, the needed change in human behaviours will most likely become a 'new normal' because it may take time to develop a vaccine.

Table 1: Records of pandemics in the past (1950-2020)

\begin{tabular}{|l|l|l|}
\hline S/N & Year & Disease Type \\
\hline 1 & $1957-1958$ & H2N2 Virus \\
\hline 2 & $1961-$ Present & Cholera \\
\hline 3 & 1968 & H3N2 Virus \\
\hline 4 & $1977-1980$ & Smallpox \\
\hline 5 & $1981-$ Present & HIV/AIDS \\
\hline 6 & $2002-2003$ & SARS \\
\hline 7 & 2009 & H1N1 Virus \\
\hline 8 & 2012 & MERS \\
\hline 9 & $2014-2016$ & Ebola \\
\hline 10 & $2018-$ Present & Ebola \\
\hline 11 & $2019-$ Present & Covid-19 \\
\hline
\end{tabular}

Sources: Past Pandemics; Centre for Disease Control and Prevention (CDC) https://www.cdc.gov Retrieved August 10, 2018

: Major Epidemics of the Modern Era (1899-2020); Council on Foreign Relation. https://www.cfr.org Retrieved 28/5/20

The World Health Organization (WHO) declared Covid-19 a world pandemic on March 11, 2020 almost three months after the virus started in the city of Wuhan, Hubei Province China when the disease met the epidemiological criteria of having infected more than 100, 000 people in at least 100 countries (Callaway, 2020). According to the Centre for Disease Control and Prevention (CDC 2020), Covid-19 complications are more pronounced in patients with underlying health conditions and immune-compromised individuals, infants and the elderly. The implication is that a person without any serious illness and with strong immune system may withstand and survive the virus and as opined by $\underline{\text { Sauer (2020) }}$ some infected persons may not even show symptoms but will be carriers of the virus while others may experience only mild symptoms and recover easily. Ohia. Bakarey and Ahmad, (2020) posited that the climatic conditions of the African continent may not be conducive for the virological characteristics of Covid-19 pathogens to survive. This is a help of a sort because most of the countries of Africa do not have the health infrastructures capable of bearing the pressure which the spread of the virus may exact on it. This is the reason why the adoption of the whole prevention 
measures is the best option for Africa in general and Nigeria in particular. Individuals should not adopt hand washing alone, should not social distancing alone and should not wear face mask alone but the combination of all the measures together to contain the spread of the virus.

Reports in the media suggest that some locals in Nigeria do not believe that the disease can infest them. Perhaps, they think the virus is meant for the rich because they do not know anyone personally infested and killed by the disease. Their attitude to the disease may be carefree as a consequence of their belief. This may invariably influence their practices and therefore spell doom for the country since they may jettison the prevention measures which are the only means to curtail the spread of the disease. A situation where asymptomatic people who are carriers of the virus have been adjudged to be more than those who will manifest the symptoms of the disease could be the reason why some locals in Nigeria think they do not know anyone personally infested. This misconception is most likely aided by the low testing capacity in Nigeria.

The Lagos State government, through its Commissioner for Health- Akin Abayomi had projected that approximately between 90,000 - 120,000 residents of Lagos State will be infested between July to August 2020. He added that majority of these people will be asymptomatic (Guardian Newspaper, May 8, 2020), thereby making increased testing a necessity to be able to curtail the possible community spread of the virus. Nigeria's economy and health system are beginning to feel the impact of Covid-19 because of its fragility. Nigeria's Director-General of the NCDC had recently announced that the country is considering the option of home treatment of mild cases of Covid-19 patients because the capacity of the isolation and treatment centres are far low to cater for new cases (Business Day Newspaper, May 8, 2020). The implications of this plan of home treatment could be enormous and may deflate the achievements recorded so far if nothing is done to get Nigerians to change their behaviours to be in tandem with the prevention measures prescribed.

The consequences of Covid-19 pandemic on the educational, social, economic and psychological well-being of individuals are huge. Consequently, the need to gauge the public perception of, practices as well as readiness for post lock down lifestyle in order to guide governments' and organizations' decisions become imperative. This study therefore attempts to assess the perception, practices of Covid-19 prevention measures and readiness for post lock down lifestyle in a community where a case or cases have been reported to see if these peoples' reactions are different from other locals who probably do not have a case/cases within their own community. This work is novel to the extent that it is the first to the knowledge of the researcher to assess locals' perception, practices of Covid-19 protocols and readiness to post lockdown lifestyle within a community with a known case of Covid-19 in Ibadan- the largest indigenous city in West Africa.

\section{Statement of the problem}

Psychological studies have shown that a change in human behaviour will be greatly influenced when individuals whose behaviours' are expected to change are personally convinced and accept that the behaviour change is necessary. This change in habits does not just happen. It requires an individual to engage in some cognitive and affective exercises. In as much as there is still no scientifically proven and acceptable drug globally for the treatment of the disease, staying safe remains the best way to staying alive. However, prevention is solely dependent on individual human behavior. One of the measures put in place to contain the spread of the virus is physical distancing which alters social interaction patterns in worship places, schools, markets, recreation centres, sports arenas among others.

Studies have been carried out on the knowledge and attitude of the people to Covid-19 in Nigeria within the first few weeks of the lockdown directive of the government. However, these studies focused on the few urban populace who had access to the internet and digital devices. In a country where the majority of the population live in the rural areas without access to technology. In addition, these studies were not specifically targeted at areas where a Covid-19 incident had been reported. 
This study sets to assess the public perception, practices of Covid-19 protocols and readiness for post lock down lifestyle in a community that has had at least a patient suffer from the disease. The outcome of this research will guide governments and organizations in taking decisions.

\section{Research questions}

1. How do the public perceive Covid-19 in a community with known incident?

2. Is the public in a community with a known Covid-19 patient practicing the preventive measures?

3. Are the people ready for the 'new normal' post lock down?

4. What are the main barriers to adoption of prevention measures (physical distancing, hand washing and face mask wearing)?

5. Are the TV, radio and online educational programmes impacting students in Ikolaba community?

\section{Literature review}

Based on the assertion of Leppin (2009) knowledge of preventive measures such as regular hand washing, using hand sanitizers, wearing face masks, respiratory hygiene, social distancing and selfisolation when sick are vital to containing widespread infection. Past studies (Choi \& Yang, 2010; Hussain, Hussain \& Hussain, 2012) have revealed that the knowledge level of an individual about an infectious disease can make him or her behave responsibly in a way that may prevent infection. Considering these studies therefore, the allusion of (Brug \& Richardus, 2009) that in order to increase the propensity of individuals to adopt precautionary measures, there may be the need to be informed about the potential risks of infections. These findings pointed to the central place of engaging in aggressive enlightenment to inform individuals about preventive measures needed to curtail any viral infection.

Similarly, a study conducted by Olapegba (2020) indicated that a large proportion of the study participants are aware and knowledgeable about Covid-19 and its presence in Nigeria. Although, it was reported that they had some varied misconceptions of the real source of the virus - some think it is a biological weapon designed by the government of China and others think it is a plague caused by sins and unbelief of human beings. These two views were the most pronounced misconceptions shared by the study participants. Also, their knowledge of precautionary behaviours (that is, hand washing, social distancing, disinfecting contaminated surfaces, closing schools, banning public events and fumigation of public places) were high.

Knowledge of precautionary behaviours may not translate into positive practices in some instances. Superstitions and ignorance of the science behind the infection is making some Nigerians prefer only to pray by gathering in churches and mosques discreetly (Abati, 2020) disobeying government directive prohibiting large gatherings. This behaviour underscores the insinuation that the plague is caused by sins, thereby resulting to spiritual orientation for solution. Perhaps, this is one of the reasons Dahab, Zandvoort, Fiasche, Warsame, Spiegel, Waldman and Checchi (2020) opined that it will be challenging to implement the preventive measures of personal hygiene and public health behaviours such as hand washing and social distancing which are necessary to curb the spread of coronavirus in many cities and rural areas in developing countries. In addition, loannidis, 2020; Vigdor, 2020, opined that the spread of Covid-19 misinformation including unsupported treatments or promotion of ineffective preventive behaviours may compound the situation. Perhaps, one way to arrest the situation- community spread of the virus, that we are witnessing already is to sustain the ban on large gatherings in Nigeria. This view is supported by the assertion of Wong, Liu, Liu, Zhou, Bi and Gao (2015) that without sustained bans of large gatherings, (including specific cultural and faith practices such as mass prayer gatherings, large weddings and funerals) it may create super-spreading events that accelerate transmission.

Mohamad, Azlan, Mohammad, Tham, and Ayub (2020), posited that the effectiveness of preventive measures to mitigate the widespread of coronavirus is highly dependent on cooperation and compliance of all members of society. They went further to say that the knowledge, attitudes and 
practices people hold towards coronavirus disease play an integral role in determining a society's readiness to accept behavioural change measures stipulated by the health authorities. From the findings of their study, it was observed that the public had good knowledge and positive attitude. However, wearing of face masks was less common in comparison to other measures. Similarly, in a study carried out by Rugarabamu, Byanaku and Ibrahim (2020), it was revealed too that the majority of respondents (84.4\%) have good knowledge of Covid-19, (96.0\%) are confident that the virus will be eliminated and $77.0 \%$ of these respondents did not go to a crowded place in recent days. The study concluded that there was a good knowledge, optimistic attitudes and appropriate practices towards Covid-19, suggesting that a community-based health awareness campaign should be sustained and intensified.

A situation where majority of a people show mild or no symptoms of the disease is a threat to the quick tracing and possible treatment of patients given the criteria for testing in Nigeria. People without known and documented symptoms may not get tested in good time because of the scarcity of tests kits and materials. The WHO (2020) reported that more than $80 \%$ of Covid-19 patients showed mild symptoms and recovered without any medical intervention. The implication of this is that the best way to contain the virus is by prevention which is done by washing of hands with soap and water and using face masks.

\section{Research methodology}

\subsection{Research design}

This study adopted the exploratory survey design. This method is deemed appropriate because it involves the collection of cross-sectional data for the purpose of describing and interpreting an existing situation under study.

\subsection{Population}

The population is the public living in Ikolaba community area of Ibadan North Local Government Area in Oyo State. This LGA was the initial epicenter of the virus in Oyo State and Ikolaba community had a case which was publicly announced on social media, radio, TV and newspaper within and outside of the State.

\subsection{Sample and sampling technique}

22 participants were selected as sample for the study. The simple random sampling technique was used in the study. The sample was drawn from a street in Ikolaba community. This sample is sufficient because saturation point seems to have been reached. According to Mason (2010) the concept of saturation is the most important factor to think about when mulling over sample size decisions in qualitative research. Similarly, Charmaz (2006) posited that saturation depends on many factors and some of these are not under a researcher's control. One of the factors includes; how much money is in the budget to carry out the study? Furthermore, Charmaz (1990, p. 1162) stated that sample used in qualitative research methods is often smaller than that used in quantitative research methods because qualitative methods are often concerned with gathering an in-depth understanding of a phenomenon or are focused on meaning which are always centred on the how and why of a particular issue, process, situation, subculture, scene or set of social interactions. He went further to assert that the aim of grounded theory and in-depth interviews is to create "categories from the data and then to analyze relationships between categories" while attending to how the "lived experience" of research participants can be understood.

\subsection{Instrument}

The survey instrument is a 10 item interview guide. The items were carefully framed in a way that respondents will express their views and not simply answer with a single word response. Respondents' perception of the disease, their attitude to, practices and preparedness for new life style were interrogated. The interview guide used for the study was given to experts in the field of evaluation to ascertain both face and content validity of the instrument. Based on their suggestions and corrections, the final instrument was deemed valid and reliable to collect the data envisaged. 


\subsection{Data analysis}

Data were analyzed using thematic analysis. This was done by initially recording participant responses to each question using a tape recorder. These responses were later transcribed and read to each participant for corrections and adoption as the true reflection of the participant views. The transcribed notes were then coded, categorized and themed. The themes found within the data are

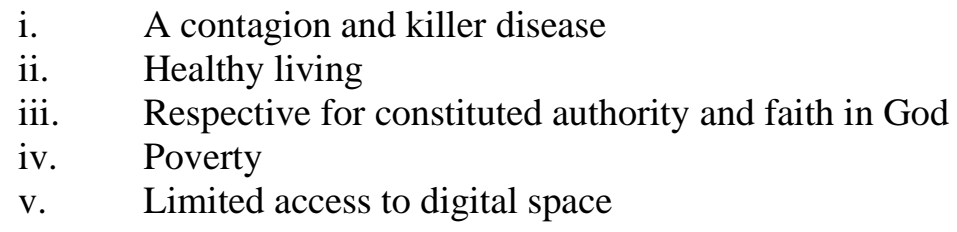

\section{Results and discussions}

Interviews were conducted with twenty-two persons living within Ikolaba community in Ibadan North Local Government Area of Oyo-State between April and May 2020. Participants' demography cuts across artisans, petty traders, business men and women, unemployed graduates, and students (undergraduate and secondary school).

Theme 1: A contagion and killer disease: the responses of the participants to the first question was categorised under this theme. How does the public perceive Covid-19 in a community with a known case? All the participants claimed to know that the disease is highly infectious and deadly. Some said that initially they didn't believe that the disease is real. Here is the excerpts from some of them

"I know that the disease is real but I also think that the disease is exaggerated and unnecessarily hyped. You will hear that someone is positive today and in a matter of days the person is negative again" - P2_M

"Sincerely, when we see reports on TV and hear on radio, I believe that the disease is contagious and deadly. Initially we did not believe but later we believe that the disease kills once it enters into someone's body"'-P3_F

This result is in tandem with the submission of Olapegba (2020) that a large proportion of the study participants are aware and knowledgeable about Covid-19 and its presence in Nigeria. It is a testament to the mass information put to the public using the mass media. Majority of the participants in this study alluded to gaining insights about the virus on the radio and television.

Theme 2: Healthy living: this theme captures the attitude of the public to the disease. A slight majority, 14 out of the 22 participants seemed to have a positive attitude to the disease. This was reflected in their following the preventive measures as stipulated by the health experts. However, the number of participants that expressed views that were negative is worrisome because to contain this virus calls for personal responsibility of all citizens. Irresponsibility on the part of a few can escalate the figures of infected persons beyond control. Excerpts from the participants with positive attitude

"I observe physical distancing...I think this virus will even help us to improve our hygienic condition because before now majority of us touch money and surfaces but will not bother to wash our hands. Wherever I go now, I wash my hands. In fact, the face mask is good too. Even after this disease some of us will be accustomed to wearing the mask because the mask protects us from dust particles that will inhale and cause some other diseases. Yes, I go out to visit friends but I observe all the preventive measures stipulated"-P5_M

"I wear my face mask regularly. I have five washable face masks and wash every day. There is so much difference between the rate at which I wash my hands in the past and now. Whenever I go visiting friends, I observe all the measures. ”-P8_M

"We should ordinarily be following these measures before now. I mean hand washing, face mask wearing and observing personal distance. Wearing of face mask can help prevent one from inhaling dust particles. We should continue with these measures after the lock down"-P14_M 
"I observe physical distancing and there is much improvement with the frequency I wash my hands. My hands are almost white now. In fact, after the disease, I will continue to observe the hygienic act of hand washing"'-P22_M

This finding corroborates the finding of Rugarabamu, Byanaku and Ibrahim, (2020) that reported the public good practices of the preventive measures to contain Covid-19. Although, the same study of Rugarabamu, Byanaku and Ibrahim (2020) also mentioned that face mask wearing had the lowest score when compared to other preventive measures practiced by the public. Similarly, some of the participants that didn't express views in tandem with positive practices have this to say

"I seldom observe physical distancing because it is very difficult to adjust to this new reality. There is no difference between the frequency at which I wash hands now and the past because as a Muslim, I pray regularly and each time, I wash my hands. The nature of my job as a vulcanizer also requires that I wash my hands after each job. I have a face mask but I don't wear it regularly except I need to enter a place where I am compelled to wear it. Anyway, destiny has a lot to do with it. Even if you stay indoors always, if God says the virus will kill you there is nothing you can do. Someone will bring the virus to your house to infest you. And it is possible you don't wear face mask, don't wash your hands and don't observe physical distancing and yet you will not be infested. Everything has to do with destiny and God. It is God that controls everything and I pray that God will stop this disease" $P 1 \_M$

"I don't observe physical distancing whenever I am in the midst of my friends. There is no difference in our ways of life at all. We still socialize the way we have been doing before. Initially when the disease broke out we were following the measures. I don't wash hands anymore although I was washing before. I will rate myself 10/100 on the use of face mask. I have visited my friends several times and they have also visited me too."-P2_M

"I must not lie, I have not been observing physical distancing. It is impossible given the kind of house we live in. There is no change in the frequency with which I wash my hands. I wash my hands just as I have been doing before because as a practicing Muslim, I pray almost every hour. I only wear face mask whenever I go to the market, that is the only place I wear it."-P14_F

Theme 3: Respect for constituted authority and faith in God is the theme for the participants' readiness for post lock down lifestyle. Based on the participants' responses, the public seem to be ready to readjust their lifestyle in conformity with the 'new normal'. Although, 20 of the 22 participants said that the new lifestyle will be highly inconvenient but that they will comply with whatever comes because of government directives. Some of them said they pray to God to take the disease away as they wish to go back to their normal lives because the virus has affected their means of livelihoods.

"I do not believe that the disease will not end. We want the end to the disease because the worship centres are the places where we can pray to God. We don't want it to take longer to end. We have faith in God that it will end soon"-P3_F

"Ah! It is not possible. God forbids. We will beg God to take this disease away. And again, we will give room for the measures since it is for our own sake. Those who have died cannot go to church or mosque or party anymore"- P11_M

"Ah! It is affecting our businesses and government is not doing anything for us self-employed. Only civil servants are protected because they receive their salary. It is not convenient for us but there is nothing we can do. It is whatever they say that we will do. It is only when there is life that one can do other things. God will sustain us." $-P 15 \_M$

"We will adjust to life because prevention is better than cure. Health is wealth. It is only when you have good health that you will aspire” - P18_M 
"It will be extremely inconvenient and at the same time, life is not constant. Therefore, as things change so should we humans be able to adapt to changes. We will have to observe the measures. What is happening now has not happened before. Since I was born, I have not heard that one should not go to the mosque or the church. Our religious leaders have also complied, we should also comply. The Holy books have it that we should respect constituted authority. If that is what will happen, it must have been destined by God."-P1_M

The result above confirms the assertion of Abati (2020) that Nigerians prefer to pray to God to help stop the disease by converging in large gatherings. While the position of Wong et al (2015) that without sustained bans of large gatherings (including specific cultural and faith practices such as mass prayer gatherings, large weddings and funerals) may create super-spreading events that accelerate transmission also finds relevance.

Theme 4: Poverty and inadequate knowledge: the major barriers inhibiting the public from adopting the preventive measures as fully required. All of the participants said that hunger and survival needs are making the people to flout the guidelines.

"Firstly, people don't follow the measures put in place because they think the disease is for the rich and also believe that they can use local herbs and remedies to treat the disease in the eventuality of contracting it." - P17_F

"The main reason why I find it difficult to observe the measures is because I do not have money. If I am financially buoyant, I would be able to stay at home."-P10_F

"People do not believe that the disease is real and they go out to look for daily bread"- P3_F

The locals are not observing the measures at all. Government should continue to enlighten the public. People do not have food and they go out to look for food daily. Civil servants can stay home and observe the measures because they will get their salary at the end of the month".-P5_M

"Everything is not about money and food. Power supply, good TV programmes and palliatives that will have direct bearing on the lives of the poor should be provided."-P13_M

"Firstly, there should be sufficient awareness. Secondly, the people should have adequate knowledge of the virus. Heads of households and Heads of communities can be of great help by leading by example." $P 2-M$

Access to digital space is a limiting factor that is hindering the efforts of the government to ensure students continued learning while at home. Almost all of the participants said that only the children of the high and the middle class are benefitting from these efforts. They posited that the majority of the students who are in the public schools are not benefitting from these educational programmes. They expressed that the efforts are good but not far reaching because the majority of students are not impacted. Consequently, they opined that regular school is the only answer for now while the digital learning infrastructure is worked on for the future. The probable reason for this view may be because they reside in a local community and do not have the wherewithal to afford internet subscription, buy a smart phone or a digital device for their children and lack the financial power to generate electricity with a generating set to power their TVs.

"Let us beg God to take this disease away so that things can go back to normal and schools can resume. This break has given most students the opportunity to wander and loaf the streets"-P1_M

"Government effort is not sufficient. Only those who are well-do can benefit from TV, radio and online learning. Someone who has not got money to eat, where will he gets money to buy data?"- P3_F

"E-learning cannot really work because we have not been doing it. We don't have the needed infrastructure. May be it can work later and we will adapt to it but for now, I don't think so."-P6_M 
"These efforts are not working because a few people have access to TV, radio and internet. I think that breaking school day into morning and afternoon sessions can work if properly organized".P8_M

"It is a good effort by the government to ensure that the students continue to learn on $\quad T V, \quad$ radio and online but the effort is not enough. Government should make access to the internet very cheap or possibly free for the poor to use. The TV and radio cannot be enough because the students will need to research on their own to add to their knowledge. It is with internet that they can get to find answer to assignment or even questions to ask their teachers." P16-F

"The government is trying because when I watched the Broadcasting Corporation of Oyo State (BCOS)- a TV station owned by the Oyo State government, they were teaching a subject. Although, some streets have organized remedial tutorials in observance of the physical distancing measure and public gathering restriction of not more than 10 people at a session. Not everybody uses a smart phone. Not everybody has internet access. Public schools have the highest number of students and most cannot benefit from the TV, radio and online learning. Schools should be opened so that this group of students can continue to learn in the school." P8_M

\section{Conclusion}

Consequent upon the severity of Covid-19 pandemic in the world today, almost every organization and government is concerned about how to cope with the pandemic. This study intended to assess the public perception, practices of Covid-19 protocols and readiness for post lockdown lifestyle in a community with a known case to find out what the perception, practices of Covid-19 protocols and readiness for post lockdown lifestyle are within it. Similar to the general public, the findings of this work have shown that the public within this community of an identified coronavirus patient see Covid-19 as a contagion and a deadly disease. In the same vein, the study reported that not all the participants practiced the preventive measures as stipulated by the health experts. Poverty was rated as the single most important factor that is inhibiting them from observing the laid down protocols that will help contain the virus. The efforts of the government on the provision of E-learning solutions were applauded as good but not all encompassing by leaving out a large percentage of the children of the poor. Hence, the need for continuous advocacy to the adherence to Covid-19 preventive measures by all and not just for the immediate benefit but for a long lasting easing of lockdown.

\section{Recommendations}

Intensive awareness and enlightenment campaigns should continue in the media. In addition to the media campaigns, community leaders should also be carried along and admonished to aggressively spread awareness and enlightenment in their domains. Findings from the study showed that the public perception and knowledge comes from what they see, hear and read on TV, radio and newspaper campaigns. Perhaps, community leaders should be motivated and enjoined to partner government in creating community awareness and campaigns on Sundays when majority of the people are at home. However, it appears the news of recoveries from the disease also poses a challenge because some locals tend to think that local herbs can also treat the disease. The views of Ioannidis, (2020); Vigdor, (2020), that the spread of Covid-19 misinformation including unsupported treatments or promotion of ineffective preventive behaviours may compound the situation is a call for circumspection. Media houses should be circumspect in the dissemination of information about recoveries. The locals in the local communities should be the focus of awareness and enlightenment going forward with emphasis on personal responsibility using direct avenues such as town halls meetings with the heads of communities playing a lead role in the campaigns.

Besides, the proposed phases of ease of lockdown is the right step in the right direction. Based on the findings, the people are willing and ready to adjust their lifestyles to suit the new reality. Government directives appeared to be followed by many in their dealings and relationships with others especially as it concerns prohibition of gatherings perhaps for fear of arrest. Some of the people even asserted that they will continue to follow some of the measures like regular washing of hands and wearing of face mask after the easing of lockdown as it is the normal sanitary practices that the public should follow with or without a pandemic situation. However, a reasonable number seemed to only wear face 
mask and observe physical distancing when forced to do so, probably before entering public places like banks and multinational corporations.

Furthermore, the e-learning efforts of the government should be redirected as it appears only the privileged children are benefitting. The government may adopt the morning and afternoon school sessions as this seems to be the only way the children of the poor can continue to learn during this pandemic period.

\section{Methodological Challenges}

Finance was a serious hindrance as the researcher wanted to cover more areas but for limited funds. Ibadan North, being a very big local government area, it was impossible to cover the entire length and breadth of the LGA. In addition, the movement restriction could not afford the researcher the opportunity to traverse the nooks and crannies of the LGA.

\section{Funding Details}

The author declares that no funding was received for the writing of this paper from any individual or corporate entity.

\section{Disclosure Statement}

The author declares that he has no known competing financial interest, benefit or personal relationships that could have appeared to influence the work reported in this paper.

\section{Biographical Note}

Andrew Abimbola Olayemi is a secondary school teacher and administrator with over 10 years teaching and administrative experience. He holds a Bachelor of Education degree in Teacher Education, Geography major and a Master of Education in Teacher Education, Social Studies Education. He is currently a Doctoral candidate in the Department of Arts and Social Sciences Education, University of Ibadan.

\section{References}

Abati, R., (2020). Corona Blues. https://saharareporters.com/2020/04/07/corona-blues-reuben-abati. Accessed June 10, 2020

Brug, A.R., Aro \& Richardus, J.H., (2009). Risk perceptions and behavior: Toward pandemic control of emerging infectious diseases: International research on risk perception in the control of emerging infectious diseases. International Journal of Behavioral Medicine. 16 (1) 3-6. https://doi.org/10.1007/s12529-008-9000-x.

Business Day Newspaper, (2020). Many Covid-19 patients not in isolation centres due to shortage of bed space by Godsgift Onyedinefu. https://businessday.ng Accessed May 8, 2020.

Callaway E. (2020). Time to use the p-word? Coronavirus enter dangerous new phase. Nature 2020. 579

Centers for Disease Control and Prevention (2020). Past pandemics. https.//www.cdc.gov last reviwed August10, 2018 retrieved May 28, 2020.

Centers for Disease Control and Prevention (2020). Human coronavirus types. National Center for Immunization and Respiratory Diseases (NCIRD) Division of viral diseases, Januray 10, $2020 . \quad$ https://www.cdc.gov/coronavirus/types.html

Charmaz, K. (1990). 'Discovering' chronic illness: Using grounded theory. Social science and Medicine, 30

Charmaz, K. (2006). Constructing grounded theory: A practical guide through qualitative analysis. London: Sage publications.

Chinenyenwa Ohia, Adeleye S. Bakarey, and Tauseef Ahmad, (2020). Covid-19 and Nigeria: Putting the realities in context. International Society for Infectious Diseases. International Journal of Infectious Diseases. 95 (2020) xxx-xxx. https://doi.org/10.1016/j.ibid.2020.04.062. https://www.science direct.com

Choi, J.S. \& Yang, N.Y. (2010). Perceived knowledge, attitude, and compliance with preventive behavior on influenza A (H1N1) by university students. J. Korean Acad. Adult Nurs 22 (3) pp. 250-259 
Council on Foreign Relations; Major epidemics of the modern era (2020). https://www.cfr.org retrieved May 28, 2020

Dahab, M., van Zandvoort, K., Fiasche, S., Warsame, A., Spiegel, P.B., Waldman, J., and Checchi, F. (2020). Covid-19 control in low-income settings and displaced populations: what can realistically be done? https://www.ishtm.ac.uk/newsevents/news/2020/covid-19-control-lowincome-settings- and-displaced-populations-what-can.

Guardian Newspaper, (2020). Lagos Government predicts 120, 000 confirmed cases by August by Dennis Erezi. https://m.guardian.ng Accessed May 8, 2020

Hussain, Z.A., Hussain, S.A., Hussain, F.A., (2012). Medical students' knowledge, perceptions and behavioral intentions towards the H1N1 influenza, swine flu, in Pakistan: a brief report. $A m$. J. Infect. Control 40 (3) e11-e13. https://doi.org/10.1016/j.ajic.2011.12.004

Ioannidis, J.P.A, (2020). Coronavirus disease 2019. The harms of exaggerated information and non-evidence based measures. European Journal of Clinical Investigation

Leppin, A.R., Aro (2009). Aro, Risk perception related to SARS and avian influenza: theoretical foundations of current behavioral research. International Journal of Behavioral Medicine 16 (1) 7-29. https://doi.org/10.1007/s12529-008-9002-8

Mason, M. (2010). Sample size and saturation in PhD Studies using qualitative interviews. Forum: Qualitative Social Research, 11(3)

Mohamad, Emma MW., Azlan Arina Anis, Mohammad Rezal Hamzah, Tham Jen Sern and Ayub, Suffian Had (2020). Public knowledge, attitudes and practices towards Covid-19: A cross sectional study in Malaysia. https://doi.org/10.1101/2020.04.29.20085563

Olapegba, P.O., (2020). A preliminary assessment of novel coronavirus (Covid-19) knowledge and perceptions in Nigeria. http://www.medrxiv.org https://doi.org/10.1101/2020.04.11.20061408

Sauer, L.M., (2020). What is Coronavirus? https://www.hopkinsmedicine.org/health/conditions-anddiseases/coronavirus. (accessed 25 March 2020)

Schoeman, D., \& Fielding, B.C. (2019). Coronavirus envelope protein: Current knowledge. Virol J $16(1)$.

Rugarabamu, S., Byanaku, A., \& Ibrahim, M. (2020). Knowledge, attitudes and practices (KAP) towards Covid-19: A quick online cross-sectional survey among Tanzanian residents. doi: https//doi.org/10.1101/2020.04.26.20080820. https://www.medrxiv.org Accessed online May 10,2020

The Econmist (2020). Covid- 19's death toll appears higher than official figures suggest. https://www.economist.com/graphic-detail/2020/04/03/covid-19s-death-toll- appearshigher- than-official-figures-suggest

Vigdor, N. (2020). Man Fatally Poisons Himself While Self-medicating for Coronavirus, Doctor Says. The New York Times. https://www.nytimes.com/2020/03/24/us/chloroquinepoisoning-coronavirus.html

Wong, G., Liu, W., Liu, Y., Zhou, B., Bi, Y., and Gao, G.F. (2015). MERS, SARS and Ebola: The Role of Suoer-Spreaders in Infectious Disease. Cell Host and Microbe, 18 https://doi.org/10.1016/j.chom.2015.09.013

World Health Organization (2020). Coronavirus International Health Topics. WHO. https://www.who.int/health-topics/coronavirus. Accessed April 3, 2020. 


\section{UNIVERSITY OF IBADAN \\ Department of Arts and Social Sciences Education}

\section{Public Perception of , Attitude to COVID-19 and Readiness for post lockdown lifestyle in Ikolaba Community, Ibadan North LGA, Oyo State.}

\section{INTERVIEW GUIDE}

1. Have you heard that coronavirus is highly infectious and deadly? What is your view about this reality?

2. Have you been observing physical/social distancing in your dealings with people? Why?

3. How often do you wash your hands now compared with pre-covid times?

4. What do you see to face mask wearing? Do you have one? Did you buy it?

5. Have you visited or intend to visit your friends lately? Or has your friends visited you recently?

6. Suppose you are invited to a party tomorrow, what will you do?

7. Suppose you are requested to continue with the prevention measures (hand washing, physical distancing, and mask wearing) for the next one year, what will you do?

8. What are the main barriers to your adoption of prevention measures (hand washing, mask wearing and physical distancing)?

9. What are the things you need in your household and community to adopt the prevention measures?

10. Are you aware of efforts by the governments to ensure that students learn even while at home through radio, TV, and online? What do you think government should do to ensure that the students continue to learn? 